\title{
Povezovanje turizma in kreativnih industrij pri oživljanju opuščene industrijske dediščine skladišča Monfort
}

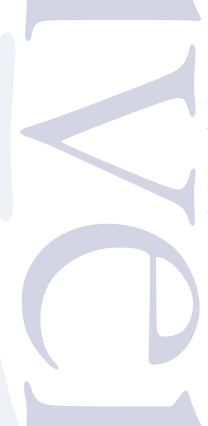

\author{
Gorazd Sedmak \\ Fakulteta za turistične študije - Turistica, Univerza na Primorskem \\ Aleksandra Brezovec \\ Fakulteta za turistične študije - Turistica, Univerza na Primorskem \\ Neža Čebron Lipovec \\ Fakulteta za humanistične študije, Univerza na Primorskem \\ Ana Plestenjak \\ Arhej, d. o. o.
}

Ştudija izhaja iz predpostavke o visoki kulturno-zgodovinski turistični privlačnosti objekta in destinacije ter priložnostih za skupno trženje turizma in kreativnih industrij. Trženjski model je zasnovan na sinergiji obeh dejavnosti, povezanih v komplementarno in trajnostno naravnano poslovno enoto, ki uposteva konkretne potrebe vseh deležnikov. Posebnost tega trženjskega modela je v prepletu aktivnosti privabljanja turistov (eksterno trženje) z aktivnostmi povezovanja notranjih deležnikov - ponudnikov kreativnih storitevy objektu (interno trženje). Model predstavlja torej enovit strateški okvir, znotraj katerega se lahko predstavniki kreativnih industrij povezujejo in povezani nastopajo na turističnem trgu, pri tem pa suvereno oblikujejo svoje specifične vizije, cilje in trženjske strategije.

Ključne besede: turizem, kreativne industrije, trženje, industrijska dediščina skladišča Monfort

The study assumes that the cultural-historical character of the site and destination possesses a high degree of attraction for tourism and that a joint marketing of tourism and creative industries is a potential. The model is based on the synergy between the two activities, connected into a complementary and sustainability-bound business unit that considers the actual needs of all the stakeholders involved. Specificity of the presented marketing model lies in the intertwining of activities to attract tourist (external marketing) and activities aimed at connecting the inner stakeholders, namely the providers of the creative industry service at the site (internal marketing). Hence, the model represents a comprehensive strategic framework, within which the representatives of creative industries can enter cooperate and team-up in the presentation on the tourist market, while also assertively design their own specific visions, goals and marketing strategies.

Keywords: tourism, creative industry, marketing, industrijal heritage of Monfort warehouse

\section{Opredelitev kreativnih industrij in njihove povezave s turizmom}

$\mathrm{P}$ ojem »kreativne industrije $\ll$ je relativno nov, zato so definicije še raznolike. Med splošno sprejetimi je opredelitev kreativnih industrij kot dejavnosti, ki proizvajajo kulturne dobrine in storitve. Natančneje so v Unescovi konvenciji iz leta 2005 opredeljene kulturne industrije, in sicer kot industrije, ki »združujejo ustvarjanje, proizvajanje in komercializacijo vse- bin, ki so kulturne narave; te vsebine so običajno zaščitene $\mathrm{z}$ avtorskimi pravicami in lahko imajo obliko blaga ali storitev«. Unescov dokument v nadaljevanju izpostavi kot pomemben vidik kulturnih industrij spodbujanje in ohranjanje kulturne raznolikosti ter zagotavljanje demokratičnega dostopa do kulture (UNCTAD 2010, 5). Z uveljavljanjem pojma kreativnih industrij pa se pri pojmovanju kulturnih industrij zgodi premik od pretežno negospodarskih h komercialnim kulturnim dejavnostim (UNCTAD 20ı, 
6). Medtem ko kulturne industrije proizvajajo in distribuirajo dobrine ali storitve, ki utelešajo ali posredujejo kulturno izražanje ne glede na komercialno vrednost (npr. scenske umetnosti, likovne umetnosti, kulturna dediščina, tudi film, novi mediji, glasba, knjige in tisk), imajo kreativne industrije kulturno razsežnost, ker uporabljajo kulturo kot vložek (npr. arhitektura in oblikovanje s podsektorji, kot so grafično in modno oblikovanje ali oglaševanje) (EU Comission 2010, 5). Skladno s tem je Evropska komisija opredelila tipologijo kreativnih industrij (FORA 20Io) (Slika I). Po tej tipologiji so kreativne industrije $\mathrm{v}$ najožjem pomenu tiste aktivnosti, pri katerih je osrednji produkt rezultat umetniške aktivnosti. Širši pomen vključuje med kreativne industrije tudi tiste dejavnosti, $\mathrm{v}$ katerih osrednji produkt sicer ni neposredna posledica kulturne dejavnosti, ima pa določene kulturne značilnosti. V najširšem smislu so pa v kreativne industrije vključene tudi panoge, katerih ekonomske aktivnosti temeljijo na umetnosti in kulturi. Primer takšne panoge je turizem (FORA 20IO).

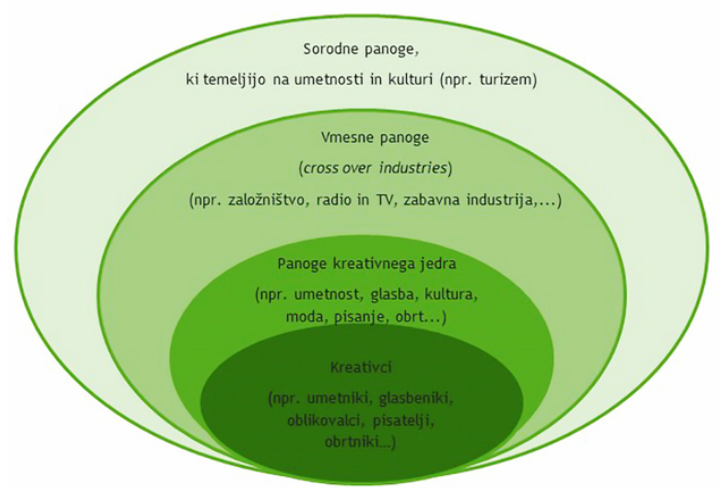

Slika I: Tipologija kreativnih industrij po FORA (2010), prirejeno v slovenskem jeziku (vir: Plestenjak in soavtorji 2018).

Navedena tipologija je omogočila razumevanje neposredne povezave kreativnih industrij s turizmom, zlasti s segmentom kulturnega turizma, ki svoje produkte in motivatorje utemeljuje na stvaritvah kreativcev.
Strokovnjaki pripisujejo kreativnim industrijam gonilno moč pri spodbujanju širše ekonomske rasti. Utemeljitev koncepta kreativnih industrij, Richard Florida skozi svoje temeljno delo The Rise of the Creative Class (2002) sporoča, da sposobnost in praksa kreiranja novih zamisli in stalnih izboljšav ultimativno dviguje produktivnost in življenjski standard. V študiji Cultural times (CISAC 2015) je ekonomski pomen kreativnih industrij tudi finančno ovrednoten: $\gg$ Kulturne in kreativne industrije $s$ prihodkom 2,250 milijard USD zagotavljajo $3 \%$ svetovnega BDP in zaposlujejo 29,5 milijonov ljudi (I \% delovno aktivne svetovne populacije) $)_{\ll}$ (CISAC 20I5). Študija, ki je bila predstavljena na sedežu UNESCA v Parizu leta 2015, pojasnjuje prispevek kreativnih industrij h globalnemu gospodarstvu ob predpostavki, da če želimo izkoristiti polni potencial kreativnih industrij, morajo biti ustvarjalci pravično plačani, da lahko nadaljujejo s svojim prispevkom h kulturi in posredno h gospodarstvu. Politični odločevalci morajo torej spodbuditi pravičen sistem prenosa vrednosti, ki bo zagotovil ustvarjalcem in s tem kreativnim industrijam sorazmeren tržni delež in pravično poplačilo za izkoriščanje njihovih del v gospodarskih panogah, tudi v turizmu.

Primer sistemske spodbude prenosa vrednosti je čezmejni projekt REFREsh - Rural Revitalisation for Cultural Heritage, izvajan v okviru programa Interreg Central Europe (20172020), s katerim Občina Piran sledi usmeritvam Republike Slovenije na področju uveljavljanja kreativnih industrij po regijah, ki bodo predstavljene v nadaljevanju. Osrednji predmet raziskave v okviru navedenega predmeta je skladišče soli Monfort v Portorožu. Po investiciji v prenovo tretje kampate (od petih) v letu 2019 je občina poverila trženje prostora Turističnemu združenju Portorož. Že doslej je prihajalo do spontanega povezovanja turizma in kreativnih industrij; z novimi prostorskimi možnostmi in sistematičnim spodbujanjem povezovanja oz. vključevanja kreativnih industrij $\mathrm{v}$ turistično ponudbo pa so se že pokazali dodatni sinergijski učinki, ki bodo spodbudili nadaljnji razvoj kreativnega de- 
lovanja v občini in obogatili turistično ponudbo destinacije. Ključna poteza projekta je vključevanje vseh relevantnih deležnikov v oblikovanje rešitev, katerim vsebinam naj bi se namenili prostori.

\section{Ukrepi na področju povezovanja} kreativnih industrij s turizmom v Sloveniji

V Sloveniji še nimamo celostne strategije za razvoj kreativnih industrij, prav tako na nacionalni ravni ne obstaja institucija kot osrednje jedro spodbujanja kreativnega sektorja, čeprav so se prizadevanja na tem področju začela že pred dobrim desetletjem. Leta 2008 je namreč vlada RS ustanovila 9. razvojno skupino za kreativne industrije, katere naloga je bila pripraviti vsebinska izhodišča državne strategije za uspešnejše uveljavljanje kreativnega sektorja (oblikovanje, arhitektura in trženjsko komuniciranje) pri ustvarjanju dodane vrednosti slovenskega gospodarstva. Priporočila 9. razvojne skupine predstavljajo prvi dokument, ki je osredotočen na kreativne industrije in ugotavlja, da Slovenija na tem področju zaostaja, čeprav osnovna strokovna infrastruktura obstaja. Problemi se pojavljajo, ker je infrastruktura slabo povezana s kreativnimi industrijami ter ker financiranje ni programsko naravnano in ne daje motivacije za povezovanje. $\mathrm{Z}$ namenom, da bi presegli to stanje, je leta 20I I Ministrstvo za kulturo RS pripravilo medsektorsko preverbo področja in izdalo knjižico za popularizacijo pojma kreativnih industrij (Breznik in soavtorji 20II). Pri definiciji so se avtorji oprli na metodologijo Eurostata in definicijo Evropske komisije, ki med drugim povezuje kreativne industrije tudi s turizmom.

$\gg$ V tem kontekstu postajajo ob tradicionalno izpostavljenih in cenjenih vrstah umetnosti, zlasti tistih, ki temeljijo na jeziku (leposlovje, dramsko gledališče, vokalna glasba), vse bolj pomembne tiste vrste umetnosti oz. kulture, ki neposredno vplivajo na razvoj države in zlasti gospodarstva ter prispevajo tudi $\mathrm{k}$ rasti BDP. Gre za kreativne industrije, od industrijskega in grafičnega oblikovanja, AV produkcije in storitev, intermedijskih umetnosti do kulturnega turizma in nesnovne kulturne dediščine oz. veščin, ki omogočajo izdelavo unikatnih proizvodov z visoko dodano vrednostjo « (Breznik Močnik in soavtorji 20II).

Leta 2018 je Ministrstvo za kulturo RS izoblikovalo Strategijo kulturne dedisčine za obdobje 2018-2026, v kateri je prav tako izpostavilo povezanost kreativnih industrij in turizma. $\mathrm{V}$ strategiji je kot razvojna usmeritev navedeno »Spodbujanje razvoja trajnostnega kulturnega turizma, kreativnih industrij in drugih novih produktov in storitev $\mathrm{z}$ uporabo dediščinskih virov«. Dediščina je prepoznana kot tista, ki je >skupaj z dejavnostmi, ki jih generira, izjemno dragocen vir za turistično-gospodarski sektor in kreativne industrije « (Direktorat za kulturno dediščino 2018, 17-18). Med ukrepi strategije sta dva eksplicitno naslovljena na kreativne industrije in turizem:

- Podpora aktiviranju dediščine za spodbujanje kulturnega turizma, kreativnih industrij in drugih načinov uporabe dediščinskih virov;

- Izboljšanje ozaveščenosti o pomenu dediščine pri zaposlenih $\mathrm{v}$ turizmu in kreativnih industrijah ter njihovo usposabljanje.

- V naboru dejavnosti tako najdemo konkretne primere, ki ponovno neposredno in posredno odpirajo možnosti za razvoj in povezovanje kreativnih industrij s turizmom:

- Vključevanje dediščine v strategije razvoja turizma Slovenije;

- Izvedba pilotnih projektov aktiviranja dediščine, ki prispevajo k razvoju trajnostnega turizma, kreativnih industrij in drugih novih produktov in storitev, povezanih $\mathrm{z}$ dediščino;

- Pri promociji turizma na določenem območju predstavljanje lokalne dediščine na vključujoč način, ki bo zagotavljal koristi tudi lokalnemu prebivalstvu in ne bo ogrožal dediščine; 
- Oblikovanje dediščinskih blagovnih znamk za trženje na področju turizma in kreativnih industrij.

Nazadnje je istega leta pod okriljem Muzeja za arhitekturo in oblikovanje, v okviru Operativnega programa za izvajanje evropske kohezijske politike v obdobju 20I 4-2020, začela delovati interdisciplinarna platforma Center za kreativnost (CzK). Naloga centra je, da »povezuje, promovira, predstavlja in podpira razvoj vseh značilnih področij kreativnega sektorja (KKS) v Sloveniji. S svojimi programi spodbuja opolnomočenje potencialov družbene in ekonomske vrednosti sektorja ter ga aktivneje povezuje $\mathrm{z}$ gospodarstvom, znanostjo, izobraževanjem in drugimi sektorji $\ll(\mathrm{CzK}$ 2019). Center, ki je finansiran s strani Evropskih kohezijskih skladov, ima v trenutnem stanju dejansko vlogo osrednje organizacije za KKI v Sloveniji. Čeprav nima formalno poverjenih nalog koordinacije, v okviru CZK nastajajo referenčni temeljni dokumenti in kot tudi primeri dobrih praks.

Izpostavljeno trojno razmerje med kulturnim turizmom, kulturno dediščino in kreativnimi industrijami predstavlja pomembno izhodišče razvoja kreativnih scen tudi v Obalnokraški regiji. Kreativne industrije so prav v tej regiji najbolj povezane s turizmom, saj se na tem območju že tradicionalno ustvarja četrtina celotnega turizma Slovenije.

\section{Razvojni potenciali kreativne scene skladišča Monfort v Portorožu}

Med turističnimi destinacijami Obalno-kraške regije ima vodilno mesto piranska občina s Portorožem kot osrednjim slovenskim letoviščem, ki na leto pritegne 500.000 gostov ter ustvari 1,5 milijonov nočitev (povprečje zadnjih pet let; vir: SURS 20I8). V sklopu projekta REFREsh smo preverjali tržne potenciale vključevanja kreativnih industrij $\mathrm{v}$ turizem pri oživljanju skladišč soli Monfort v Portorožu. V okviru projekta je Občina Piran, poleg že razvitega terciarnega sektorja (turizem), pristopila k spodbujanju kreativnih industrij tudi v sekundarnem sektorju, in sicer v okviru tradicije pridobivanja soli (rudar- jenje), ki je značilno za to območje. Razvoj turizma je namreč $\mathrm{v}$ Portorožu že tradicionalno povezan s solinarstvom, saj se je turizem na tej destinaciji pojavil prav skozi razvoj zdraviliških storitev $\mathrm{z}$ uporabo stranskih produktov pridobivanja soli. Tako se je portoroški samostan San Lorenzo (sedanja lokacija hotela Metropol) že v 13. stoletju omenjal kot zdraviliški kraj, ki je slovel po zdravilnih učinkih solinskega blata in slanice iz piranskih solin. Sodobna turistična dejavnost se je v Portorožu začela razvijati v drugi polovici 19. stoletja, ko so kraj tržili kot privlačno kopališko destinacijo in v luksuznih vilah ponujali kapacitete za turistične namestitve. Kopališču in prvemu hotelu, ki sta bila v Portorožu zgrajena leta I89ı, so hitro sledile nove investicije in leta 1897 je bil Portorož (Porto Rose presso Pirano, natančneje območje od Metropolovega griča do Bernardina) uradno razglašen za klimatsko zdravilišče. Razcvet je portoroški turizem začel doživljati po izgradnji hotela Palace leta I9ı in $\mathrm{z}$ vzpostavitvijo mednarodne letalske povezave (hidroport ob Monfortu) (Gombač in Brezovec 2007,43$)$. Turistični razvoj območja sta začasno prekinili obe svetovni vojni, vendar se je v obdobju po priključitvi Jugoslaviji in s tem Sloveniji, razvoj portoroškega turizma intenzivno stopnjeval. Po zasnovi arhitekta Eda Mihevca in temeljiti prenovi kraja v letih $1965-76$ je postal Portorož vodilna turistična destinacija in eden od stebrov slovenskega turizma, kar je ostal vse do danes. Po aktualnem razvojnem načrtu (Strategija razvoja turizma v občini Piran do leta 2025; Lesjak, Brezovec in Fabjan 2018) se portoroški turizem usmerja $\mathrm{k}$ trajnostnemu razvoju, pri čemer se v ospredje postavljata kultura in dediščina kraja. V smislu kulturno-kreativnih industrij se v Portorožu nadaljujejo tradicije glasbenih, filmskih in oglaševalskih festivalov, ki so se skozi desetletja že intenzivno vpeli v turizem. Prav tako je turistično aktivno delovanje sečoveljskih solin, ki skozi znamko tako Krajinskega parka Sečovlje kot podjetja Soline dodaja novo vrednost solinskim izdelkom in turističnim storitvam v Portorožu. $S$ tematskim oživljanjem skladišč soli Monfort bi se lahko trženje 


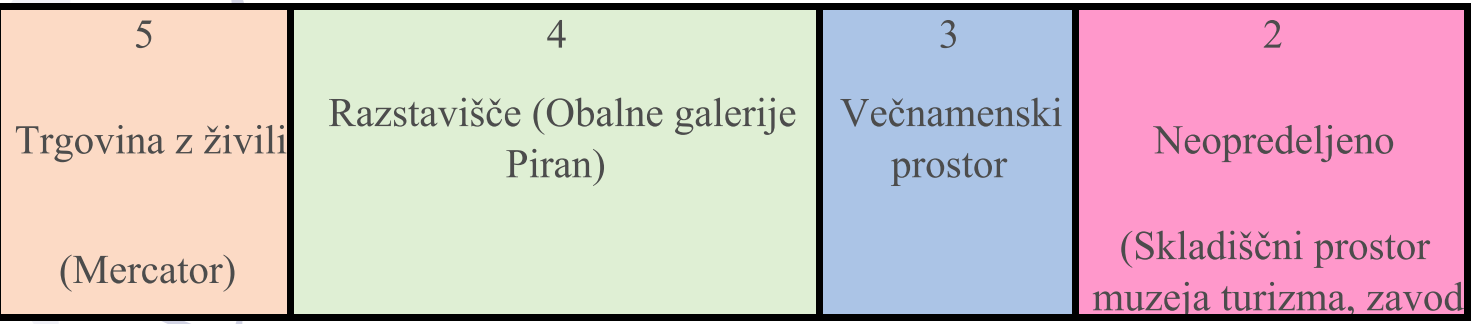

Slika 2: Trenutna raba prostorov v objektu Monfort (vir: Plestenjak in soavtorji, 20I8).

izdelkov in storitev razširilo tudi na druge kreativne industrije $\mathrm{v}$ kraju in s tem pospešilo kulturni turizem. V ta namen je bila skozi projekt REFREsh opravljena valorizacija skladiščne stavbe Monfort.

\section{Metodologija valoriziranja objekta $v$ kulturno turistične namene}

$\mathrm{Z}$ namenom pridobivanja nabora idejnih rešitev glede vsebin je bilo v sklopu projekta organiziranih več delavnic, fokusnih skupin in sestankov $s$ predstavniki različnih skupin deležnikov (lokalna skupnost, predstavniki kreativnih industrij, GIZ Portorož), kjer se je zbiralo ideje, izmenjevalo mnenja in stališča ter snovalo možne strateške usmeritve glede vsebin, ki naj bi bile umeščene v objekt, ter sinergij, ki naj bi iz teh izhajale. Predlaganih je bilo več vsebin s področja glasbene ustvarjalnosti (glasbena šola, vadnice za mlade glasbene skupine, snemalni studio, ...), likovne in vizualne ustvarjalnosti (animacija, ročne spretnosti), ustvarjalnosti (animacije, ročne spretnosti ...), športno-rekreativnih aktivnosti (joga, ples, sodobni ples, ...) in družabnega življenja (kartanje, šah, biljard, rojstnodnevna praznovanja otrok ...). Med predlogi je bilo kar nekaj vsebin, ki v občini že obstajajo in katerih podvajanje ne bi bilo smiselno, potencialno težavo pa predstavljajo tudi nekompatibilne aktivnosti oz. vsebine. Za lažje odločanje smo zato opredelili nekaj ključnih kriterijev vključevanja in povezovanja dejavnosti KKI:

- ne podvajanje vsebin, ki že imajo ustrezne pogoje za delovanje,
- kompatibilnost dejavnosti z osnovnim namenom prostorov,

- sorodnost in kompatibilnost vsebin oz. področij delovanja,

- sorodnost poslanstva/vrednot/motivov (raven komercialnih ambicij, vplivati na kakovost življenja v lokalni skupnosti, druženje podobno mislečih ...) nosilcev dejavnosti,

- kraj bivanja/delovanja nosilcev/izvajalcev dejavnosti (prednost imajo lokalni oz. regionalni akterji),

- kompatibilnost potrebnih resursov in možnosti sinergij ter oblikovanja verig vrednosti in

- medsebojna kompatibilnost glede ciljnih skupin uporabnikov.

\section{Kreativne funkcije prostorov $v$ Monfortu}

$\mathrm{V}$ skladišču Monfort, ki je razdeljeno na pet dvoran (kampat), so kreativne industrije že sedaj aktivne. Ena od kampat je namenjena trgovini $\mathrm{z}$ živili, v vseh ostalih kampatah pa se izvajajo programske vsebine, ki jih večinoma izvajajo kreativne industrije.

$\mathrm{V}$ prvi kampati je stalni razstavni prostor Pomorskega muzeja »Sergej Mašera «, Piran. V tej kampati je tudi manjša predavalnica ter info točka. V prizidku so urejene sanitarije. Pomorski muzej »Sergej Mašera« zbira, proučuje in predstavlja pomorsko preteklost slovenskega obalnega področja, slovensko pomorsko preteklost in na pomorstvo vezane gospodarske panoge. V Monfortu predstavlja zbirki Tradicionalno ladjedelništvo in Razvoj vodnih športov. $\mathrm{V}$ info točki je trenutno postavljena razstava 


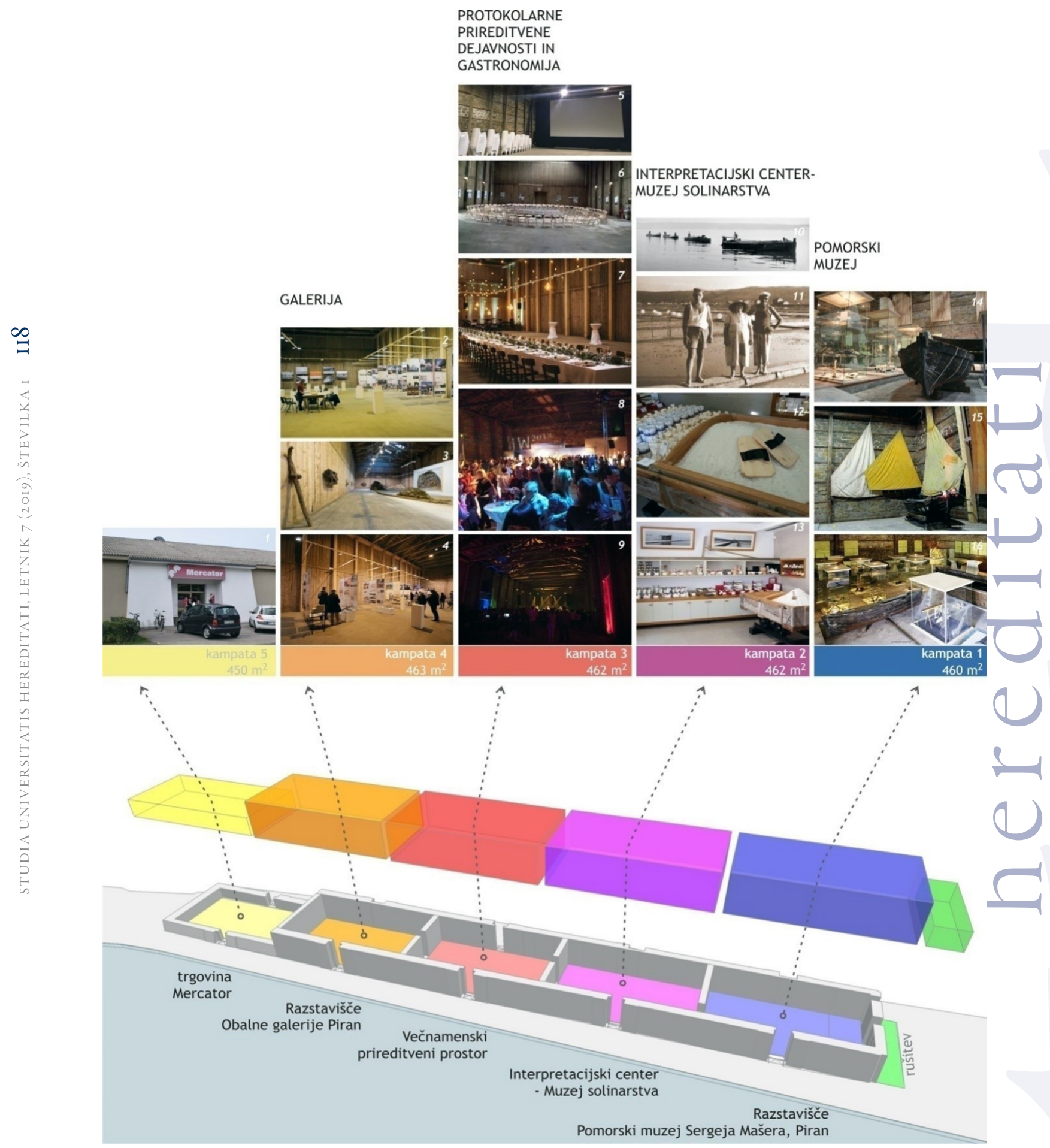

Slika 3: Pregled kreativnih funkcij prostorov v Monfortu (vir: Plestenjak in soavtorji 2018). 
o solinarstvu, kjer je predstavljena tudi zgodovina nastanka skladišč in razvoja območja. V četrti kampati so stalni razstavni prostori Obalnih galerij Piran, osrednje galerijske institucije v Obalno-kraški regiji .

V drugi kampati je bil do nedavnega urejen skladiščni prostor muzeja turizma (zavod Mediteranum); skupaj s tretjo kampato pa prostor ni imal stalnih vsebin, zato se je občasno oddajala v najem za različne prireditve (koncerti, razstave, športni in kulinarični dogodki, poroke). Lastnica objekta, Občina Piran, je želela tovrstno rabo objekta ohraniti oz. še povečati kreativno rabo kampat. Z namenom oživitve objekta, povečanja števila dogodkov ter učinkovite turistične promocije, je Občina Piran januarja 2019 s Turističnim združenjem Portorož sklenila Pogodbo o trženju dvorane št. 2 in 3 skladišča soli - Monfort. V sklopu projekta REFREsh so bile v študiji Koncepti revitalizacije za skladǐčce Monfort (GEArt 20I8) preučene možnosti programskih zasnov za tretjo kampato; analiza je bila nato razširjena na celoten objekt Monforta ter vključila tudi sosednji objekt nekdanjega skladišča Grando. Različne programske vsebine so bile analizirane v Študiji izvedljivosti vključevanja kulturnih scen $v$ razvoj industrijskih območij: primer skladišč soli Monfort in Grando v Fizinah (Plestenjak in soavtorji 20I8). $\mathrm{Na}$ osnovi teh analiz je bil podan predlog novih vsebinskih poudarkov, kot prikazuje Slika 3. Skladno z željami investitorja so bila sočasno, spomladi 2019, izpeljana gradbena dela za prenovo notranjščine tretje kampate skladišča Monfort za potrebe raznolikih prireditev.

\section{Model trženja skladišča Monfort kot centra kreativnih industrij}

V okviru projekt REFRESh smo za objekt Monfort razvili tudi strateške usmeritve trženja $s$ poudarkom na umeščanju vsebin in povezovanju kreativnih industrij s turizmom. Pri usmeritvah smo poleg že omenjenih kriterijev upoštevali tudi naslednja izhodišča:

- $\quad$ skladnost s strateškimi cilji za razvoj kreativnih industrij v državi oziroma regiji,
- skladnost s strateškimi cilji občine Piran,

- dvig kakovosti življenja lokalne skupnosti (središče dogajanja in kulture za prebivalce).

Za opredelitev smernic trženja prostora $s$ kreativnimi vsebinami predlagamo in utemeljujemo naslednje usmeritve:

a) usmeritve glede marketinških ciljev,

b) usmeritve glede vrst dejavnosti/vsebin,

c) trajnostni koncept trženja $\mathrm{z}$ vključitvijo internega trženja,

d) usmeritve glede segmentacije trga uporabnikov in tržnega pozicioniranja.

Celovito marketinško strategijo smo razvili skozi lasten model, ki nakazuje izhodišča in usmeritve ter povezave med njimi. Model je zasnovan na predpostavki o razvoju Monforta kot centra kreativnih industrij v Portorožu, ki omogoča dolgoročno korist za razvoj kreativnosti regije ter lokacije Portorož. Trženja Monforta zato ne usmerjamo le k privabljanju obiskovalcev / turistov (t.i. eksterno trženje), ampak tudi $\mathrm{k}$ povezovanju ponudnikov, ki svoje dejavnosti vključujejo v okviru Monforta, ter $\mathrm{k}$ prebivalcem območja (t.i. interno trženje). Interno trženje, ki ga splošne marketinške strategije redkeje opredeljujejo, predstavlja varovalko trajnostnega razvoja kreativne scene na turistični destinaciji, zaradi specifike kulturnih dejavnosti, ki v osnovi niso tržno naravnane. Interno trženje se na eni strani usmerja $\mathrm{k}$ raziskovanju in preverjanju potreb interne javnosti (najemnikov oziroma izvajalcev kreativnih dejavnosti na lokaciji), na drugi strani pa razvija in izvaja učinkovito komuniciranje z njimi - jih povezuje, motivira, ozavešča, izobražuje in usposablja za doseganje zastavljenih ciljev kreativnosti kraja in širše regije. Povezovanje ponudnikov oz. najemnikov Monforta se bo razvijalo skozi orodja t.i. simbioznega trženja (imenovano tudi sodelovalno ali soustvarjalno trženje).

Sestavni del marketinške strategije za Monfort je seveda tudi klasično eksterno trženje, s katerim se usmerjamo na odjemalce kreativnih dobrin oziroma obiskovalce objekta. Te bomo 


\section{IDENTITETA LOKACIJE}

\section{STRATEŠKA USMERITEV DEJAVNOSTI: CILJI, VRSTE}

\section{TRAJNOSTNO TRŽENJE}

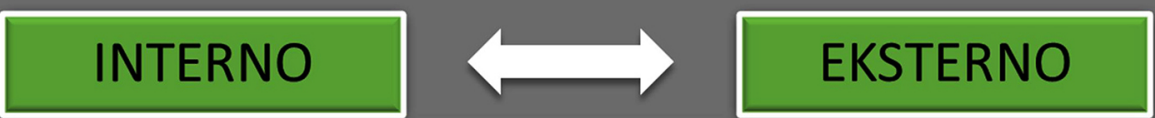

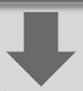

Povezovanje najemnikov

Simbiozno trženje

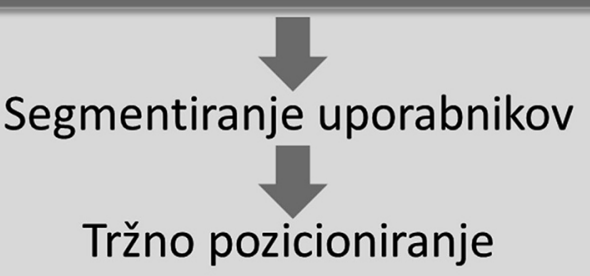

Slika 4: Pregled kreativnih funkcij prostorov v Monfortu (vir: Plestenjak in soavtorji 2018).

segmentirali v zaokrožene razlikovalne skupine s skupnimi značilnostmi. Tem skupinam se bo s skupnimi trženjskimi orodji (skupni komunikacijski kanali, cenovne politike in standardi storitev in doživetij) predstavljalo tržno pozicijo.

$\mathrm{Za}$ učinkovito trženje Monforta kot kreativne scene $\mathrm{v}$ Portorožu priporočamo novejši okvir, t.i. ${ }_{4} \mathrm{C}$ model, ki pomaga kreativcem, da $\mathrm{v}$ fazi trženja postavijo na prvo mesto vidik uporabnika kreativnih dobrin in storitev. Tradicionalni marketinški modeli (npr. ${ }_{4} \mathrm{P}$ - proizvod, cena, distribucija, promocija) se namreč že v osnovi osredotočajo na oblikovanje trgu primernega proizvoda, kar po našem mnenju ne ustreza humanistični naravi kreativnih industrij. Kreativni sektor - za razliko od gospodarstva - namreč primarno kreira dobrine iz notranjih vzgibov ustvarjalcev samih. Izravnati kreativni sektor z gospodarsko ravnjo marketinškega zadovoljevanja potreb trga, ne sme postati cilj strategije spodbujanja kreativnih scen na destinacijah.
Dejstvo pa je, da ustvarjalci lažje dosežejo uporabnike svojih dobrin, če sklopu spodbujanja kreativnosti dodamo znanja in veščine s področja trženja. Pri marketinškem pristopu ${ }_{4} \mathrm{C}$ bomo pri trženju Monforta upoštevali:

CI) kakšne so značilnosti uporabnikov določenih kreativnih dobrin (angl. customer),

C2) kakšna je najprimernejša/najprikladnejša oblika ponudbe določene kreativne dobrine (angl. convenience),

C3) kakšen je celoten strošek, ki ga je uporabnik pripravljen nameniti uporabi/nabavi kreativne dobrine (npr. ne le cena ampak tudi pot do kraja) (angl. costs),

$\left.\mathrm{C}_{4}\right)$ kakšen je učinkovit dialog z uporabniki oz. kako doseči dvosmerno komunikacijo z njimi (ne le enosmerne promocije) (angl. communication) (Londhe 2014). 
Z upoštevanjem marketinškega modela ${ }_{4} \mathrm{C}$ omogočamo kreativnim industrijam, da najprej prepoznajo in segmentirajo skupine, ki so možni odjemalci/uporabniki njihovih dobrin, nato pa pri ponudbi upoštevajo, kako te skupine iščejo informacije o kulturnih dobrinah, kako se odločajo zanje ter kje in kako jih lahko najenostavneje naročijo oz. kupijo. S pomočjo ${ }_{4} \mathrm{C}$ lahko torej ponudniki kulturnih dobrin plasirajo svojo ponudbo preko pravih kanalov tistim skupinam ljudi, ki jim kulturna dobrina predstavlja vrednost in so zanjo pripravljeni nameniti svoj prihodek, čas in energijo. Nazadnje pomaga ${ }_{4} \mathrm{C}$ tudi pri komuniciranju $\mathrm{z}$ obstoječimi in potencialnimi uporabniki, tako da jih vključi v dialog in celo $\mathrm{v}$ soustvarjanje. $S$ primernimi komunikacijami, čeprav tržnimi (npr. utrjevanje imidža, blagovne/tržne znamke, pospeševanje prodaje, oglaševanje ipd.) lahko kreativne industrije presežejo odnos ponudnik - kupec in ustvarijo odnos ustvarjalec - uporabnik in celo ustvarjalec - soustvarjalec.

\section{Strateške smernice trženja Monforta Usmeritve glede ponudbe}

Strateške usmeritve o tem, katere kreativne dejavnosti (dobrine in storitve) tržiti v obravnavanem objektu, smo valorizirali skozi tri ključna vprašanja:

I) Katere dejavnosti/proizvode labko ponudimo na obravnavani lokaciji? (npr. predlog Občine Piran glede na strategijo, interese in zmožnosti)

2) Katere dejavnosti/proizvode želimo ponuditi na obravnavani lokaciji? (predlog stroke, npr. Turističnega združenja Portorož, ki izvaja analize in strateške usmeritve)

3) Kakšni bodo (dolgoročni) učinki dejavnosti tega prostora za kraj?

Predlogi kreativnih dejavnosti, ki izhajajo iz analize stanja, analize potreb deležnikov, analize ponudnikov in analize trendov, so:

a) Primarne dejavnosti: umetnost in kultura (povezana s krajem, dediščino, lokacijo, pre- bivalci); npr. likovne in fotografske razstave, nastopi amaterskih kulturno-umetniških skupin, literarna srečanja; dejavnosti kreativnega sektorja, ki omogočajo (so)ustvarjanje skozi kreativne delavnice, co-working in druženje; npr. razvijanje AV in IKT rešitev;

b) Dopolnilne dejavnosti: kreativni dogodki, doživetja, prireditve, rekreacija; npr. plesne delavnice, joga ...

c) Neželene dejavnosti: množične zabavne prireditve (neustrezna infrastruktura in neposredna bližina bivalnega naselja); zgolj komercialno oddajanje prostora $\mathrm{v}$ najem $\mathrm{za}$ aktivnost, ki nima pozitivnega kreativnega ali promocijskega potenciala za lokalno okolje (npr. poroke ali rojstnodnevna praznovanja).

\section{Usmeritve glede trajnostnega trženja}

Da bodo marketinške aktivnosti pomagale dvigovati prepoznavnost in dolgoročni ugled lokacije, je treba v dolgoročno sodelovanje zajeti tri ključne subjekte:

- najemnike (ustvarjalce) kot interne deležnike

- obiskovalce (turiste) kot eksterne deležnike in

- partnerje (soustvarjalce).

\section{Najemniki}

Monfort kot kreativno središče združuje ponudnike kreativnih industrij $\mathrm{v}$ kraju. Kreativni ponudniki se lahko vključijo v aktivnosti Monforta na podlagi različnih potreb (npr. poceni najem prostora za svojo dejavnost, skupna uporaba osnovnih sredstev, potreba po svetovanju). $\mathrm{Za}$ dolgoročno učinkovito trženje Monforta je potrebno segment najemnikov prostora razvrstiti v segmente sedanjih in segmente potencialnih najemnikov. Za obstoječe najemnike, katerim omogočamo potrebne vire in usklajujemo pogoje ter aktivnosti skupnega trženja, pripravimo načrt internega komuniciranja. Skozi interno tržno komuniciranje utrjujemo potrebne stand- 
arde ponudbe Monforta (način in kanali prodaje, način interpretacije, organizacijska kultura), spodbujamo povezovanje in ustvarjanje nove vrednosti (novi dogodki, doživetja, ponudba, zgodbe). Za potencialne najemnike pa pripravimo načrt eksternega tržnega komuniciranja, $v$ katerem predstavimo pomen in vlogo Monforta kot kreativne scene v Portorožu ter priložnosti in koristi za najemnike (npr. zakaj najeti prav ta prostor za protokolarni dogodek, za co-working, za razstavo, koncert...).

Ključna elementa diferenciacije in konkurenčne prednosti Monforta sta arhitektura in zgodba/ dediščina, ki izhaja iz osnovne namembnosti. Usmeritve $\mathrm{v}$ zvezi s privabljanjem najemnikov (ustvarjalcev) so:

- primernost prostora za izvedbo kulturno-kreativne dejavnosti,

- visoka kulturno-kreativna in podjetniška kompetentnost najemnika,

- raznolikost kreativnih dejavnosti za potrebe doseganja sinergij interdisciplinarnosti ter $s$ tem razvoj novo kreativnosti na lokaciji.

\section{Obiskovalci}

Vrste dobrin in storitev, ki jo v Monfortu ponujajo najemniki prostora, so tiste, ki določajo vrste obiskovalcev (turistov). Ti so:

- kupci dobrin ali storitev stalnih najemnikov v Monfortu (npr. obiskovalci muzejev in galerij),

- udeleženci, ki se izobražujejo in družijo skozi aktivnosti v Monfortu (npr. obiskovalci delavnic),

- obiskovalci prireditev in dogodkov v Monfortu (glasbenih, literarnih, promocijskih),

- obiskovalci Monforta kot arhitekturne (zgodovinske, dediščinske) znamenitosti kraja.

Navedene kupce in obiskovalce ločimo glede na značilnosti Portoroža kot turistične destinacije na domačine in turiste, te pa nadalje na podsegmente, ki sledijo tržnim segmentom tu- rističnega sektorja v kraju. Po zadnjih segmentacijskih raziskavah gre za dva večja podsegmenta, in sicer za pretežno tuje turiste, nastanjene $\mathrm{v}$ portoroških hotelih, ki prihajajo z motivom uživanja v obmorskem okolju, ter za starejše pretežno slovenske $\gg$ ljubitelje narave Primorja $\ll$. Poleg omenjenih je še več manjših segmentov, kot so t. i. »iskalci kulturne avtentičnosti «, »mladi željni zabave $\ll$ in $\gg l j u b i t e l j i ~ k a m p i r a n j a \ll$ (Sedmak in Mihalič 2008).

Usmeritve v zvezi s privabljanjem obiskovalcev so:

- prepoznavnost in pozitiven kreativen imidž Monforta,

- trajnostna rast števila domačih in tujih obiskovalcev,

- medijska pokritost vsebin in aktivnosti Monforta za dvig zavedanja o pomenu kreativnega delovanja za širšo javnost/kraj/regijo.

\section{Partnerji}

Kot partnerje kreativnega središča Monfort opredeljujemo fizične in pravne osebe, s katerimi se lahko upravljavci povežejo s ciljem dolgoročnega uspešnega delovanja in trženja svojih aktivnosti. Partnerje smo opredelili glede na vrsto sektorja (kreativne industrije, gospodarstvo, izobraževanje), glede na lokacijo (turistične organizacije, tri univerze v občini) ter glede na obseg sodelovanja (npr. IKT podpora, raziskovalna dejavnost).

Usmeritve v zvezi s pritegovanjem partnerjev so:

- vzajemno koristni odnosi in razvoj kraja za bivanje in turistični obisk,

- $\quad \mathrm{v}$ javnosti priznana družbena korist delovanja tega prostora,

- prenos znanj in informacij v okolje za dvig kreativnosti in inovativnosti,

- raznolikost sektorjev, iz katerih prihajajo. 


\section{Tržna segmentacija}

Pri opredelitvi tržnih segmentov smo izhajali iz dveh ključnih vprašanj:

- Komu predstavljajo dejavnosti kreativnih industrij posebno vrednost?

- S kakšno kombinacijo kriterijev razvrstiti uporabnike $\mathrm{v}$ prepoznavne, dosegljive in merljive skupine obiskovalcev?

Za odgovore na ti dve vprašanji smo segmentirali obiskovalce/turiste glede na vrsto kreativnih industrij in glede na njihove lastnosti.

a) Glede na vrsto kreativnih industrij se osredotočimo na dve vrsti segmentov:

- uporabniki kreativnih dobrin (npr. kupci umetniških del in izdelkov umetnostne obrti, kupci oblikovalskih izdelkov, publikacij, novih medijev)

- uporabniki kreativnih storitev (npr. obiskovalci kulturnih ustanov, razstav in prireditev).

b) Glede na lastnosti uporabnikov pa se po metodologiji prepoznavanja osebnih lastnosti t.i. person (Valicon 2016) osredotočimo na naslednje tržne segmente oz. »persone«:

- t.i. raziskovalci (zanimajo jih doživetja, kultura, odločajo se na spletu...)

- t.i. urbani potrošniki (zanimajo jih muzeji, prireditve, grafiti...)

- t.i. aktivni nostalgiki (zanima jih lokalna kultura, dediščina, o ponudbi se informirajo na lokaciji...)

- t.i. lepotni navdušenci (zanima jih moda, dizajn, kulinarika, informirajo se na spletu...)

- t.i. brezskrbni mladi (zanimajo jih prireditve, koncerti, zabava, preizkušajo stereotipe...)

- t.i. večno mladi (aktivni upokojenci, zanima jih kultura, zgodovina, uporabljajo tiskane medije...)

- t.i.foodiji (zanima jih eno-gastronomija, prezentacija lokalne hrane, zgodovina...).

\section{Tržno pozicioniranje}

Monfort se mora glede na svojo identiteto pozicionirati kot arhitekturna atrakcija (v oblikovnem in dediščinskem smislu), pri čemer mora izpostaviti vrednost prostora in kreativnih vsebin. Od konkurence (npr. drugih muzejskih in galerijskih stavb, ter drugih prireditvenih prostorov $\mathrm{v}$ kraju/regiji/državi), se loči prav po svoji arhitekturno-dediščinski zapuščini ter privlačni obmorski mikrolokaciji. S tem lahko omogoča drugačno izkušnjo in dodano vrednost izvajanja in konzumiranja ponujenih kreativnih vsebin.

Glede na izsledke predhodnih analiz stanja in okolja, je marketinško podobo oziroma kreativno znamko Monforta smiselno razvijati v tri smeri:

- umetnost (likovna, glasbena, film, literatura),

- ohranjanje in interpretiranje dediščine (muzeji, razstave in dogodki, izdelki in storitve povezani z identiteto kraja/regije) ter

- festivalska dejavnost (glasba, filmi, oglaševanje, eno-gastronomija).

$S$ temi vsebinami določamo prioritete razvoja, ciljne segmente uporabnikov ter komunikacije $\mathrm{v}$ domačem in mednarodnem okolju. $\mathrm{Na}$ vse tri osrednje dejavnosti grajenja podobe kreativnega sektorja je možno in potrebno navezati tudi ostale kreativne industrije, ki bodo skozi sodobno oblikovanje in $s$ trajnostnim pristopom povezovale ustvarjalnost domačinov in doživljajsko izkušnjo obiskovalcev.

Po načelu povezovanja turizma in kreativnih industrij je turizem smiselno uporabiti kot kanal oz. "izložbeno okno" pri trženju kreativnih dobrin in storitev Monforta. Prav tako je smiselno slediti odprtosti definicije kreativnih industrij, ki dopuščajo širitev nabora klasifikacij glede na arbitrarno odločitev, kaj v nekem kraju sodi v kreativni sektor. Povezovanje kreativnih industrij in turizma je uspešneje, če kreativnost odraža avtentičnost kraja in časa, ki ju delimo s turisti. Tako nam primer Genove kaže, da je možno med kreativne industrije uvrstiti tudi sektor hrane in pijače, primeri Merana, Nice in 
Opatije pa, da je tudi sam turizem (zgodovina in dediščina turizma kraja) že postal del kreativnih industrij (npr. muzeji turizma).

\section{Simbiozno trženje kreativnih industrij in turizma}

Monfort naj v prvi vrsti povezuje ključne sektorje in kreativne subjekte za doseganje dolgotrajnih pozitivnih učinkov kreativnih industrij za lokacijo. Simbiozno, imenovano tudi sodelovalno ali soustvarjalno trženje, lahko pomembno prispeva $\mathrm{k}$ trajnostnemu razvoju združenih ponudnikov in lokacije. Za razliko od tradicionalnega trženja, $\mathrm{v}$ okviru katerega (turistični) ponudniki skrbijo le za razvoj proizvodov, cen, distribucijskih kanalov in promocije, se s simbioznim trženjem kreativnih industrij zasledujejo:

- $\quad$ širše koristi kreativne scene za kraj / regijo,

- celovita vrednost uporabe Monforta za ponudnike, uporabnike in partnerje,

- prilagajanje okoliščinam, ki vplivajo na dejavnosti in uporabo/obisk Monforta (npr. trendi, vreme, politika),

- cilji prepoznavnosti in komuniciranja $\mathrm{z}$ različnimi javnostmi.

Analiza stanja in potreb po kreativni sceni $\mathrm{v}$ Portorožu kaže na potrebo po vertikalnih in horizontalnih povezovanjih ponudbe in promocije. Za trajnostni razvoj kreativnih industrij v Monfortu se morajo zato združiti resursi, procesi in programi trženja med istovrstnimi ponudniki (npr. muzeji, umetniki, oglaševalci) ter med vertikalno komplementarnimi ponudniki (npr. ponudniki turističnih storitev, raziskovalci, kreativni izvajalci). Vrste možnih oblik sodelovanja med internimi deležniki so so-uporaba in razvoj komunikacijskih in prodajnih kanalov (interaktivne spletne strani in e-trgovina, blogi itd.), skupno oz. koordinirano iskanje možnosti za učinkovito valorizacijo učinkov kreativnih industrij, povezovanje z zasebnim sektorjem na področju kreativnih marketinških storitev, s sekcijami gospodarske zbornice in tudi z javnim sektorjem. Nenazadnje je, kot že omenjeno, v Piranski občini tudi veliko odprtih možnosti za sodelovanje z raziskovalno-izobraževalnim institucijami pri spodbujanju povezav med kreativnimi industrijami in turizmom. Glede na težo, ki jo ima v tem okolju, izpostavljamo zlasti možnosti sodelovanja z Univerzo na Primorskem, katere pridružena članica je tudi Fakulteta za dizajn, neposredno vpeta v razvoj kadrov kreativnih industrij. $\mathrm{Ob}$ njej so kreativne vsebine posredno ali neposredno prisotne tudi na drugih fakultetah, npr. portoroška Fakulteta za turistične študije - Turistica, kjer izobražujejo in raziskujejo kulturni, dediščinski in inovativni turizem, koprska Pedagoška fakulteta in Fakulteta za humanistične študije, ki pokrivata področje umetniške dejavnosti in medijev, Fakulteta za management, kjer razvijajo design management in podjetniške kompetence, ki so potrebne za učinkovito in uspešno valorizacijo učinkov kreativnih industrij. V povezavi z univerzo je treba omeniti tudi Center odličnosti InnoRenew CoE - neodvisni raziskovalni inštitut, ki spodbuja kulturo odprtih inovacij s poudarkom na interdisciplinarnemu proučevanju lesa in njegove uporabe $s$ ciljem razvijati konkurenčno prednost regije in države.

Ključna gospodarska dejavnost, s katero se mora razvijati simbiozno trženje kreativnih industrij v Monfortu, je turistično gospodarstvo. Turistični ponudniki lahko oblikujejo s kreativnimi industrijami sinergije na področju vključevanja kreativnih industrij v turistično ponudbo in na področju inovativnega tržnega komuniciranja turistične destinacije. V sklopu različnih že izpeljanih projektov povezovanja turizma in kreativnih industrij v občini so: Kreativne ideje za podjetniško soustvarjanje novih turističnih proizvodov (KIPSNTP), Wellness Istra, TURIZEM 4.0 - obogatene turistične izkušnje, Izkusimo istrsko podeželje: novi (tematski) turistični produkti in njihova promocija (TURIZMO IŠTRIANO), Skupna dediščina za skupno mednarodno promocijo 365 dni zelenega turizma na Opatijski in Portoroški rivieri (Riviera4Seasons2), Quality Network on Sustainable Tourism (QNeST), 
Komunizem in turizem: sodobne prezentacije in interpretacije s pomočjo informacijske tehnologije (TITOUR).

\section{Zaključek}

$\mathrm{V}$ članku smo prikazali pomen, priložnosti in metodologijo povezovanja turizma, dediščine in kreativnih industrij na primeru Monforta v Portorožu. Gre, kot kažejo nekateri primeri iz tujine, za izredno kompleksno, hkrati pa potencialno zelo perspektivno kombinacijo dejavnosti oz. področij, kjer se pojavlja vrsta možnih sinergij. Medtem ko sta turistični in dediščinski vidik skladišč soli bila $\mathrm{v}$ preteklosti že deležna več resnih obravnav, so kreativne industrije še dokaj neraziskano in slabo razumljeno področje, kar bo pri implementaciji predlaganih rešitev gotovo predstavljalo velik izziv. Poleg šibke raziskanosti so kreativne industrije specifične tudi zaradi notranje heterogenosti - tako vsebinske in organizacijske kot konceptualne, kar zahteva fleksibilnost pristopov in obravnav tega segmenta $\gg$ trojčka $\ll$.

$S$ pomočjo analize strateških dokumentov, pregleda teoretičnih podlag in primerov dobrih praks ter terenskega dela in sestankov z različnimi deležniki smo prišli do nabora priporočljivih vsebin skladišča in oblikovali teoretični okvir simbioznega trženja Monforta. Ta upošteva tako strateške smernice piranske občine, načela varovanja dediščine in trajnostnega delovanja, predstavlja pa lahko tudi primerno osnovo za sorodne primere povezovanja obravnavanih dejavnosti.

$\mathrm{V}$ nadaljevanju bo potrebne veliko kontinuirane multilateralne komunikacije med vsemi identificiranimi deležniki, da se bo predlagani okvir smiselno napolnil s konkretnimi vsebinami. Ključni organizacijski akter bi morala pri tem biti občinska uprava, upoštevajoč, da pri tej vlogi ne gre le za en projekt, ampak je spodbujanje in podpora aktivnemu usklajevanju in povezovanju vseh deležnikov strateškega pomena za uspešen razvoj občine.

\section{Povzetek}

Skladišča soli Monfort in Grando v Portorožu sta industrijska dediščina zaščitena kot spomenika lokalnega pomena. Skladišče Monfort je bilo predmet analize in prenove v okviru Interreg projekta REFREsh (pod okriljem Zavoda za varstvo kulturne dediščine Slovenije), s ciljem da se določi nova namembnost, ki bi temeljila na kreativnih industrijah. V ta namen je bila narejena interdisciplinarna študija, $s$ katero so bili oblikovani predlogi za nove rabe ter modeli trženja teh rab. Model trženja skladišča Monfort kot centra kreativnih industrij, ki vključuje tudi povezovanje s turizmom, predvideva aktivnosti eksternega in internega trženja. Prvo bo usmerjeno $\mathrm{k}$ prepoznavanju potreb in privabljanju obiskovalcev/kupcev/turistov (to so npr. obiskovalci muzejev, delavnic, prireditev ...), drugo pa k ponudnikom oz. najemnikom prostorov in prebivalcem območja. Pri eksternem trženju je ključna segmentacija in prilagoditev ponudbe in trženjskega spleta posameznim segmentom (domačim oz. tujim turistom, različnim psihografskim segmentom, kot so iskalci avtentičnosti, mladi željni zabave itd.). Namen tega dela trženja je zadovoljevanje potreb obiskovalcev in zagotavljanje finančne uspešnosti delovanja najemnikov/ponudnikov. Pri internem trženju pa je ključno razumevanje potreb internih javnosti (najemnikov oziroma izvajalcev kreativnih dejavnosti na lokaciji in lokalne skupnosti), z namenom učinkovitega komuniciranja z njimi - s ciljem ozaveščanja, povezovanja, motiviranja, izobraževanja in usposabljanja za doseganje zastavljenih ciljev kreativnosti kraja in širše regije. Skozi interno tržno komuniciranje se oblikujejo in utrjujejo standardi ponudbe Monforta (način in kanali prodaje, način interpretacije, organizacijska kultura) ter spodbuja povezovanje in ustvarjanje nove vrednosti (novi dogodki, doživetja, ponudba, zgodbe). Monfort se mora glede na svojo identiteto pozicionirati kot arhitekturna-dediščinska atrakcija na privlačni obmorski mikrolokaciji, pri čemer mora izpostaviti vrednost prostora in kreativnih vsebin. Za doseganje dolgotrajnih pozitivnih učinkov kreativnih industrij za kraj predlagamo simbiozno ali soustvarjalno trženje, ki predvideva povezovanje ponudbe in promocije tako na horizontalni (med istovrstnimi ponudniki - npr. muzeji, umetniki, oglaševalci) kot vertikalni (npr.s ponudniki turističnih storitev, raziskovalnimi inštitucijami ...) ravni. 


\section{Summary}

The warehouses of Monfort and Grando in Portorož are protected as cultural heritage and listed as monuments of local importance. Monfort warehouse has been subject to analysis and renovation within the REFREsh Interreg project (under the aegis of the Institute for the protection of cultural heritage of Slovenia), with the aim to identify a re-use linked to creative industries. For this purpose, an interdisciplinary research was carried out which formulated proposals for new uses and the related marketing model. The marketing model for Monfort warehouse as a centre for creative industries, which integrates also links with tourism, envisages external and internal marketing activities. The former aims at identifying needs and attracting visitors/buyers/ tourists (i.e. Visitors to museums, workshops, events etc.), and the latter to providers or tenants and residents of the area. In the external marketing, segmentation and adaptation to the offer and marketing mix to individual segments (domestic or foreign tourists, different psychographic segments, such as authenticity seekers, young people seeking entertainment etc.) is crucial. This section of marketing aims at meeting the needs of the visitors and ensuring the financial performance of tenants/providers. In the case of internal marketing, understanding the needs of internal publics (tenants or creative industry providers at the site and local community) is crucial in order to communicate effectively with them - with the aim of raising awareness, connecting, motivating, educating and training for achieving the set goals to develop creativity of the place and the wider region. Through internal market communication, Monfort's offering standards (manner and channels of sale, method of interpretation, organisational culture) are formed and consolidated, while promoting connection and creation of new values (new events, experiences, offer, stories). Monfort has to position itself as an architectural and heritage attraction on its attractive seaside micro-location, highlighting the value of space and creative content. To achieve long-lasting positive effects of creative industries for the area, we suggest a symbiotic or co-creative marketing, which involves linking supply and promotion to both horizontal (between similar providers - e.g. museums, artists, advertisers) and vertical (ed with tourist service providers, research institutions ...) level.

\section{Literatura in viri}

Breznik Močnik, M., Lipovšek, B., Pivec, H., Stepančič, L., Širca, M. in Tivadar, B. 20II. Kulturne in kreativne industrije po slovensko, Ministrstvo Republike Slovenije za kulturo. https://tovarna.org/fileso/ active/3/brosura-web-si.pdf

Center za kreativnost. 2019. "O nas". https:// www.czk.si/O_nas.

CISAC. 2015. "Cultural times, The first global map of cultural and creative industries." https://en.unesco.org/creativity/sites/ creativity/files/cultural_times._the_first global_map_of_cultural_and_creative_ industries.pdf

Direktorat za kulturno dediščino, Ministrstvo za kulturo RS Slovenija. 20r8. "Strategija kulturne dediščine za obdobje 20ı82026; Osnutek (12.2.2018)”. Ljubljana: Ministrstvo za kulturo. http://www. mk.gov.si/fileadmin/mk.gov.si/ pageuploads/Ministrstvo/Zakonodaja/ Predpisi_v_pripravi/2018/Strategija_ KD_2018-02-19.pdf.

EU Commission. 2010. "Greenpaper. Unlocking the potential of cultural and creative industries". https:// op.europa.eu/en/publication-detail/-/ publication/Icb6f 484-074b-4913-87b3344 ccforoeef/language-en

Florida, R. 2002. The Rise of the Creative Class: And How It's Transforming Work, Leisure, Community and Everyday Life. New York: Basic Books.

FORA. 20ro. "New Cluster Concepts Activities in Creative industries". Copenhagen: FORA, Danish Enterprise and Construction Authority's Division for Research and Analysis - http://www. rosted.nu/attachments/File/2010/creative_ industries.pdf

GEArt. 20I8. Študija izvedljivosti koncepta revitalizacije v objektu Monfort. Nazarje: GEArt, Vizualne komunikacije d.o.o. 
Gombač, S. in Brezovec T. 2007. Letalas sidrom. Hidroavioni v Portorožu in okolici. Ljubljana: Tehniška založba Slovenije.

Lesjak, M., Brezovec, T. in Fabjan, D. 2018. "Strategija razvoja turizma v občini Piran". Univerza na Primorskem, Fakulteta za turistične študije - Turistica, Portorož. Dostopna na https://www.portoroz.si/si/ files/default/PDF/Partnerji/Strategija\%2O rzavoja\%2oturizma\%2oob\%c4\%8dine $\% 20$ Piran\%2odo\%2oleta\%202025.pdf

Londhe, B. R. 2014. "Marketing Mix for Next Generation Marketing”. Procedia Economics and Finance. Dostopno na www.sciencedirect.com 2212-567I (C) 2014 Elsevier B.V. http://creativecommons.org/ licenses/by-nc-nd/3.0/

Plestenjak, A., Vesenjak, A. in Čebron Lipovec N. 2018. "Študija izvedljivosti vključevanja kulturnih scen v razvoj industrijskih območij: primer skladišč soli Monfort in Grando v Fizinah.” Interna študija projekt REFRSh. Ljubljana, Zavod za varstvo kulturne dediščine Slovenija.

Sedmak, G., Mihalič, T. 2008. "Authenticity in mature seaside resorts." Annals of Tourism Research, 35 (5), 1007-1031.

UNCTAD. 2010. "Creative economy report 20Iо”. https://unctad.org/en/Docs/ ditctab20103_en.pdf

Valicon. 2016. "Persone ciljnih skupin slovenskega turizma." Poročilo projekta. Dostopno 30.10.2019 na: https://www. slovenia.info/uploads/dokumenti/ raziskave/stors7_persone_ciljnih_skupin_ slo_turizma.pdf 